\title{
Assimilation through Marriage
}

\author{
Gil S. Epstein ${ }^{1}$ \\ Bar-Ilan University, IZA Bonn and CReAM London
}

Renana Lindner Pomerantz ${ }^{2}$

Bar-Ilan University

\begin{abstract}
During the last few decades cultural changes have been taking place in many countries due to migration. The degree to which the foreign culture influences the local culture, differs across countries. This paper shows how the willingness of locals and immigrants to intermarry influences the culture and the national identity of the host country. We use a search-theoretic approach to show that, even in situations where migrants and natives prefer to marry within their own community, the search process may lead to intermarriage. The exogamy can take on two forms: either migrants and natives each hold on to their own culture or the immigrants take on the natives' culture. In the first case we will see new cultures developing and the local culture will not survive over time. In the second case the local culture will survive. We show the conditions for assimilation versus no assimilation between the groups.
\end{abstract}

Keywords: Assimilation, Migration, Marriage, Culture.

JEL classification: F22, R23

\footnotetext{
${ }^{1}$ Corresponding author's e-mail: Gil.Epstein@biu.ac.il

Financial support from the Adar Foundation of the Economics Department of Bar-Ilan University is gratefully acknowledged.

${ }^{2}$ This is part of Renana Lindner Pomerant's PhD at Bar-Ilan University, Ramat-Gan Israel.
} 


\section{Introduction}

Samuel P. Huntington's book: "Who are we? The Challenges to America's National Identity" deals with what he perceives as a potential threat to the American national identity, due to the growth in the number of Latin-American migrants and their descendants. Huntington is concerned that extensive immigration could "divide the United States into two peoples, two cultures and two languages". The book, published in 2004, was criticized by many who claim that it reflects Nativism. Fraga and Segura (2006) see the book as an opportunity to evaluate the claim that the American national identity is threatened by the growth among native-born and immigrant populations of Latin American origin, particularly - but not exclusively - Mexicans. The question of the nature of national identity which arises due to migration is relevant not only in the United States but also in Europe. The integration of immigrants in general, and those from Muslim countries in particular is one of the challenges that many Western countries face nowadays. Fukuyama (2006) mentions that Europeans claim, with some justice, that they face a harder problem in integrating their immigrants - the majority of whom are Muslims - than does the United States, where the majority of immigrants share the Christian heritage of the dominant native cultural group. Different countries have different attitudes and policies regarding this issue. Moreover, the degree to which foreign cultures influence the local culture and national identity differs across the globe. Fukuyama (2006) mentions, for example, the difference between the nationalist legacy of Germany and the pluralism and tolerance of the Dutch. Another interesting example, mentioned in his paper, is France. The French republic, in the classical form, refused to recognize separate communal identities, and indeed uses the power of the state to homogenize the French society. However, with the growth of terrorism and domestic violence, an intense discussion has emerged in France regarding the reasons behind the failure of this form of integration. Part of the reason may be that the French themselves gave up their traditional concept of citizenship in favor of a trendier approach of multi-culturalism.

The main channel through which migration influences on culture and national identity of the hosting countries, is the assimilation of the migrants into the local population. One way to assimilate is through the labor market. The question of assimilation and integration into the labor market of the host country has been widely analyzed in the literature (see for example, Boeri, Hanson and McCormick (2002), 
Bauer, Lofstrom and Zimmermann (2000) and Venturini (2004)). According to the standard economic models in this field, the degree of assimilation is influenced by individual factors, the characteristics of the home and host countries, the migration motive, and the expected migration duration. The greater the similarity between the sending and the receiving countries, i.e. the type of ethnic goods each country consumes, the more rapid the assimilation. ${ }^{34}$ Various indicators were used to measure the degree of assimilation. The most common measures, in the economic literature, are wages and earnings. It has been shown that, for immigrants and their descendants, as the length of time in the host country increases and assimilation occurs, earnings tend to approach those of comparable local workers, and, in some cases, migrants even out-perform the local workers. Other indicators include labor force participation, poverty, and education. 5

Another form of assimilation is the intermarriage between the natives and the immigrants. According to Meng and Meurs (2009), 35\% of the French male immigrants and $33 \%$ of the French female immigrants intermarry. They claim that European immigrants have the highest probability of intermarriage (46\% and 50\% for males and females, respectively), while less than six per cent of Turkish women and nine per cent of Turkish men intermarry. The proportion of intermarriage for immigrants from African countries is around twenty per cent. We thus see that intermarriage, especially in Europe, is very common. Meng and Gregory (2005) see intermarriage as a way for the immigrants to acquire host country customs, language skills, and knowledge of the local labor market, and to obtain contacts and connections. It improves their job prospects and increases the rate of economic assimilation. Furtado and Theodoropoulos $(2009,2010)$ show that marrying a native

\footnotetext{
3 On the concept of ethnic human capital, Chiswick (2009) shows that economic determinants of 'successful' and 'disadvantaged' group outcomes are sensitive to the relationship between ethnic and general human capital, especially with regard to externalities in the processes by which they are formed. Policies which welcome ethnic diversity within the larger society, without encouraging separation, would be desirable. A genuinely inclusive policy of multi-culturalism would also be beneficial.

4 Studies of migrants around the world show, with a few exceptions, that they tend to earn wages substantially lower than those of the comparable local population (see for example Chiswick (1978) and Borjas (2000)). To a degree, this reflects a failure on the part of the migrants to make the effort to assimilate. The "lack of effort" may well be different for the legal and illegal migrants. In general it can arise from a desire to maintain a cultural heritage or a separate identity, which would be lost or reduced if the group assimilated. The failure to take active steps to assimilate can also arise in the face of high adjustment costs, such as inadequate language skills, inter-generational or familial conflicts, and ignorance regarding the host country's labor market.

${ }^{5}$ On assimilation and culture see also Epstein and Gang (2010a, 2010b).
} 
increases the immigrant's employment probability by approximately four per cent through accessing to local networks. Bisin and Verdier (2000) concentrate on another aspect of intermarriage; the desire of parents to transmit their own cultural traits to their children. In this sense, each individual's choice of a marriage partner crucially determines his/her ability to transmit his/her set of cultural traits to the children. This is because in a heterogeneous marriage a member of a minority group will have a difficulty transmitting his/her own traits to the children, since the spouse will favor a different set of traits. Therefore, to transmit their cultural identity to their offspring, individuals from a cultural minority have higher incentives to marry homogenously and to exert socialization efforts. Thus, the population converges to a heterogeneous distribution, in which minorities are never fully assimilated. The authors claim that this explains the failure of the "melting pot" theory of assimilation. A similar argument is presented in Bisin, Topa and Verdier (2004), regarding inter-religious marriage. ${ }^{6}$

In this paper, we claim that intermarriage between natives and immigrants plays an important role in explaining the changes on culture and identity in United States and the European countries. Using a search-theoretic model in the marriage market, we show that the willingness of individuals to intermarry results in different patterns of exogamy, which may have different effects on the national identity of countries.

We assume that each individual is required to make two decisions: first regarding his own identity (whether to keep his own customs or to assimilate) and second, regarding the identity of those he agrees to marry. In order to emphasize our results, we assume that migrants and natives prefer to marry within their own community. However, we show that even under this assumption, the search process may yield intermarriage and assimilation. Specifically, we obtain that under certain conditions the equilibrium is not the one where each individual is married to a partner from his own community, rather, we obtain an exogamy equilibrium. We show conditions under which intermarriage can take two forms: $a$. intermarriage where the native and the immigrant hold on to their own culture and $b$. one of the parties adopts the culture of their partner. These equilibrium are important to study since in the first

\footnotetext{
${ }^{6}$ One other possibility could be an information process under which people use information others have and thus discriminate based on information they do not have assuming others have the available information, see for example Bauer et al (2009) and Epstein (2010).
} 
case, the children of the couple are brought up in a household where the parents have different views, an upbringing that could affect the children and create a new culture. Thus, the culture of the natives the "old" culture will fail to survive over time, and a new culture can develop. On the other hand, if the migrant adopts the local culture, we will see assimilation and over time, the natives' culture will survive. We therefore see that the type of intermarriage influences the culture and the national identity of the hosting country, and can explain the differences in the change in culture in certain countries, over time.

Before turning to the model, we would like to mention another important contribution of our paper to the economic literature, and specifically to the searchtheoretic models. The search-theoretic literature focuses on two main markets: the labor market and the marriage market. In many models of search, individuals are assumed to be identical, and the focus is on the matching function which determines the number of matches only as a function of the participants (Diamond (1982), Mortensen (1982) and Pissarides (1990)). In other papers, the individuals are assumed to be heterogeneous, in the sense that there is an exogenous characteristic which distinguishes between them. For example, Cornelius (2003) distinguishes between "good companions" and "bad companions", where the quality of each individual is assumed to be exogenous and no-one can change his type. Other examples are Mortensen and Pissarides (1999) and Shimer and Smith (2000) for the labor market, and Burdett and Coles (1997) for the marriage market. Exogenous characteristics which distinguish between individuals and are not changeable can be, for example, race, age, etc. However, in reality, there are also many endogenous characteristics determined by the person itself, which distinguish people. For example, people decide on their level of religious observance, their political attitudes, the language they speak, their clothing, and so on. This paper takes the search-theoretic models one step further, by assuming that the type of the individual is endogenous and everyone chooses his own type. Decisions regarding type or identity are especially relevant when we talk about immigrants who are required to decide whether to remain loyal to their own identity or assimilate, adopting the norms of behavior of the local population. By providing the individuals in our model with the opportunity to change their identity by assimilating, we examine how their choice of identity, in addition to their marriage decisions, influences the dynamics of national identity over time. 


\section{The Model}

Assume a continuum of unmarried individuals looking for spouses represented by the unit interval $u=[0,1]$. A fraction $p \in(0,1)$ of this group are natives $(n)$ and a fraction $(1-p)$ are immigrants $(m)$. For simplicity, we assume that the size of the single group is constant, as are the proportion of immigrants and natives in the group. This means that when a couple marries and leaves the market, another single man and another single woman enter the market, and the type of the new players (natives or immigrants) is identical to the type of the leaving players (steady-state). In addition, we assume that $p>1-p$, i.e., $\mathrm{p}>0.5$ which means that the natives are the dominant ethnic group.

We assume that individuals can change their type and join the other ethnic group, meaning that migrants can assimilate and natives can take on the migrants' customs. An individual can adopt the customs and behavior of the other ethnic group by wearing their clothing, adopting their language, etc. By doing so he integrates into this group.

Each individual has two decisions to make: $a$. regarding his identity and social ethnic belonging (whether to keep his ethnic group's customs or join the other ethnic group by adopting their customs) and $b$. regarding his marriage (whether to consider marrying someone from the other ethnic group or not). We assume that changing social belonging and/or marrying someone from the other ethnic group is costly. Specifically, we assume that if an individual remains in his own group and in addition marries someone from his own group, this yields him a periodic payment of one However, changing one's social belonging or marrying someone from the other group yields a lower periodic payment. The periodic payment of a single individual is zero, which means that no one prefers remaining single forever.

In order to capture all these assumptions, we assume the following periodic payment for a married native:

$$
r N_{x}^{y}=e^{-(x-n)^{2}-\theta(y-n)^{2}}
$$

And for a married immigrant:

$$
r M_{x}^{y}=e^{-(x-m)^{2}-\theta(y-m)^{2}}
$$


Where: $x \in\{n, m\}$ - represents the actual belonging of the individual, namely the behavior adopted; $y \in\{n, m\}$ - the actual behavior of his spouse; $\theta$ - the sensitivity of the individual to the behavior of his spouse.

It can be seen, that when $x=y=n$ for the native (or: $x=y=m$ for the immigrant), the periodic payment for a married individual is 1 , whereas when $x \neq n$ and/or $y \neq n$ for the native (or: $x \neq m$ and/or $y \neq m$ for the immigrant) the periodic payment and hence the life time utility is lower.

We would like to mention, that for a married individual $y$ represents the actual social belonging of the spouse, and not his original belonging. We assume that the moment an individual takes on a different culture he adopts it at once and his original ethnic belonging is not observable.

Before proceeding, we would like to raise another point. One can imagine a situation where individuals prefer to marry an individual from the other ethnic group. For example, it could be that immigrants prefer to marry natives in order to improve their integration process. If this is the case, a little change is required in the utility function of the individuals. We will stick to our original assumption (natives prefer natives and immigrants prefer immigrants) but we mention that assimilation would be enhanced if we would change this assumption while other main results would not be altered.

As we can see, (1) and (2) represent the payment to an individual after deciding about his social belonging and finding a spouse. The periodic payment of a single is zero; however he has potential benefits in the future, depending on the social belonging of his spouse. Formally, $r N S_{x}$ that stands for the periodic utility of a Native Single with a behavior characterized by $x$, is:

$$
r N S_{x}=\alpha\left(\lambda \max \left\{N_{x}^{n}-N S_{x}, 0\right\}+(1-\lambda) \max \left\{N_{x}^{m}-N S_{x}, 0\right\}\right)
$$

$\alpha$ - represents the arrival rate of potential spouses where it is assumed that they arrive according to a Poisson process; and $\lambda$ - represents the proportion of individuals belonging to the native group in equilibrium (this is an endogenous parameter which does not necessarily equal the original proportion $p$ ). 
Similarly, $r M S_{x}$ stands for the periodic utility of an Migrant Single with a behavior characterized by $x$, and is equal to:

$$
r M S_{x}=\alpha\left(\lambda \max \left\{M_{x}^{n}-M S_{x}, 0\right\}+(1-\lambda) \max \left\{M_{x}^{m}-M S_{x}, 0\right\}\right)
$$

Equations (3) and (4) tell us that a single individual dates potential spouses in a Poisson process with an arrival rate of $\alpha$, and marries them if this yields him a utility which is higher than the expected utility from continuing in the search process.

In our framework we do not allow for divorce. Therefore once a couple gets married they stay together forever.

From equations (1)-(4) we may derive the following results: 1. Each individual prefers to marry someone from his own ethnic group rather than someone from the other group: $N_{x}^{n}>N_{x}^{m}, M_{x}^{m}>M_{x}^{n}$. This is also valid for an individual who chooses to change his own identity and social ethnic belonging by adopting the other group's customs, meaning that every individual prefers a marriage with someone from his original group. 2. Each individual prefers to marry someone from his own ethnic group rather than remaining single: $N_{x}^{n}>N S_{x}, M_{x}^{m}>M S_{x}$. Knowing this, we now compare marriage with someone from a different social group to remaining single and continuing the search process.

\section{Proposition 1:}

An individual who was born as a native (no matter how he behaves in equilibrium) prefers remaining single rather than marrying an immigrant if and only if $\lambda>\frac{r}{\alpha} \frac{1}{e^{\theta(n-m)^{2}}-1}$. An individual who was born as an immigrant (no matter how he behaves in equilibrium) prefers remaining single to marrying a native if and only if $1-\lambda>\frac{r}{\alpha} \frac{1}{e^{\theta(n-m)^{2}}-1} .^{7}$

For proof see appendix.

\footnotetext{
${ }^{7}$ Notice again, that the marriage preferences of immigrants and natives do not depend on their actual belonging but only on their origin. This is based on our assumption that individuals always favor people from the same background as their own.
} 
As mentioned, $\lambda$ represents the proportion of individuals in the singles population who behave in equilibrium as natives, and $(1-\lambda)$ those behaving in equilibrium as immigrants. When the proportion of people who adopt the norms and behavior of the local population, by neglecting their original customs, is sufficiently high, the natives reject marriage opportunities with immigrants and prefer to wait for future opportunities of marriage with natives. Turning to the immigrants' point of view, when the group of immigrants in the singles population is high enough, the immigrants prefer remaining single over marriage with natives. However, when the immigrants are a minority in the population, they avoid the risk of remaining single and prefer marrying natives.

Let us try and understand the conditions presented in Proposition 1. Taking the derivative of $\frac{r}{\alpha} \frac{1}{e^{\theta(n-m)^{2}}-1}$ with respect to the different variables, we obtain:

\section{Proposition 2:}

The probability for a native-immigrant marriage increases with:

\section{1. the interest rate $r$.}

and decreases with:

1. the Poisson arrival rate $(\alpha)$,

2. the sensitivity of the individual to the identity of his spouse $(\theta)$

3. the cultural difference between natives and immigrants $\left((n-m)^{2}\right)$.

When the rate of interest, or actually the discount factor, increases, the individual's preference for the present over the future increases. Consequently, the individual prefers to compromise rather than waiting for someone else, and marries his current date. However, when the arrival rate of potential spouses increases, the individual prefers to wait and continue the search process. This is also the case when the sensitivity of the individual to the identity of his spouse or the cultural difference between natives and immigrants increases. 


\section{Equilibrium}

As stated above, each individual in our model has to consider two decision variables. First, regarding his own social ethnic belonging (whether he remains loyal to his original customs or adopts the customs of the other ethnic group), and second regarding the identity of his acceptable spouse (whether he agrees to marry someone from the other ethnic group or not). Notice, that hereinafter we will refer to an individual who agrees to only marry someone from his own original ethnic group as "selective" 8 . An individual who agrees to marry someone from the other ethnic group will be called unselective. Equilibrium exists when no one can benefit by changing one or more of his decision variables.

In the next section we examine the following potential equilibria:

1. Segregating Equilibrium - all the individuals in the singles population remain in their original social group (natives behave as natives and immigrants as immigrants) and all of them are selective, that is agree to only marry individuals from their own group.

2. Exogamy Equilibria:

a. Exogamy without Assimilation - the individuals are unselective and agree to marry their first date (meaning that there are intermarriages) but each individual holds on to his own culture.

b. Exogamy with Assimilation - one group takes on the other group's culture, resulting in homogeneous couples (husband and wife behave the same).

In the next section we examine the conditions for these potential equilibria to hold.

\subsection{Segregating Equilibrium}

As mentioned above, equilibrium exists when no one can benefit by changing one or more of his decision variables: his own social belonging and which spouses are acceptable.

\footnotetext{
${ }^{8}$ We mention again that this is true even if the individual himself changes his behavior.
} 
Proposition 3: A Segregating Equilibrium exists when the two following conditions are satisfied:

a. $1-p>\frac{r}{\alpha} \frac{1}{e^{\theta(n-m)^{2}}-1}$

b. $\frac{\alpha(1-p)}{r(r+\alpha(1-p))}>\frac{\alpha p e^{-(1+\theta)(n-m)^{2}}}{r(r+\alpha p)}$

The calculations that yield the conditions for this and the other equilibria are detailed in the Appendix. We mention, as detailed in the Appendix, that the first condition above is concerned with the marriage decision and the second condition with maintaining identity decision.

The proposition yields the following corollary:

\section{Corollary 1:}

a. When the cultural difference between the natives and the immigrants is small enough the Segregating Equilibrium does not exist. This is also the case when the individuals' sensitivity to the identity of their spouses is minimal $(\theta=0)$.

$b$. When the cultural difference between the natives and the immigrants is large enough the Segregating Equilibrium always exists.

c. For every $p$, there exists a minimal cultural gap which is necessary for the Segregated Equilibrium to hold. This minimal gap is an increasing function of $p$.

The first part of the corollary deals with a situation when there is almost no cultural difference between the local population and the immigrants. When this is the case, the decision to separate in marriage is not stable (condition $a$ does not hold) and the singles prefer to marry someone from the other group rather than continue in the search process. In addition, the minority easily agrees to change its identity and integrate into the majority group (condition $b$ also does not hold). This coincides with the literature on migration, which shows high levels of assimilation in situations where the cultural differences between the migrants and natives are small (see for example, Venturini (2004)). 
When the individuals' sensitivity to the identity of their spouses is minimal ( $\theta=0$ ), no matter what the gap between the groups is, condition $a$ in the proposition does not hold, which again means that to be separated in marriage is not the best response.

Regarding the second part of the corollary, when there is a significant difference between the customs of the natives and the customs of the immigrants, everyone prefers keeping their own identity and avoiding marrying members of the other group. This means that the Segregating Equilibrium holds regardless of the inner division of the singles' population between natives and immigrants.

The third part of the corollary links the proportion of natives in the singles population to the cultural gap between the natives and the immigrants. As the proportion of natives increases, the immigrants' incentive for intermarriage is enhanced and they will only choose to segregate for a higher cultural gap.

In a way, we can refer to the Segregating Equilibrium as quite intuitive. This is because our initial assumption, represented by equations (1) and (2), that each individual prefers his own community and culture, and the best solution for everyone is to remain loyal to their own customs, and find a spouse with the same background. Nevertheless, in the next two sections we show that even under these preferences, exogamy can be equilibrium.

Notice that there can be a situation where only the larger group, the natives in our framework, is selective, while the smaller group (migrants) is unselective. This yields separation in marriage because the unselective group has no choice but to marry individuals from their own group. Hence, this leads to a segregated society due to the exclusion against the minority by the majority group. These circumstances lead to a higher degree of social tension than the mutual segregating equilibrium that we discussed above. 


\subsection{Exogamy without Assimilation Equilibrium}

Proposition 4: The Exogamy without Assimilation situation is an equilibrium when the population is balanced, in the sense that the gap between the proportions of immigrants and natives in the population is small enough.

Formally, the algebraic condition for the Exogamy without Assimilation to be an equilibrium is when $p<\frac{r}{\alpha} \frac{1}{e^{\theta(n-m)^{2}}-1}$. This means that there is an upper bound to the proportion of natives in the population and hence we obtain that the immigrants are a significant group in the population.

The algebraic condition yields us the following corollary:

\section{Corollary 2:}

a. When the cultural difference between the natives and the immigrants is small enough, or when the individuals' sensitivity to the identity of their spouses is minimal $(\theta=0)$, the Exogamy without Assimilation is always an equilibrium.

$b$. When the cultural difference between the natives and the immigrants is large enough the Exogamy without Assimilation is never an equilibrium.

The first part of the corollary deals with a situation where the cultural difference between the local population and the immigrants is small enough and where the individuals' sensitivity to the identity of their spouses is minimal $(\theta=0)$. In both cases the Exogamy without Assimilation is an equilibrium for every value of $p$, which means that individuals agree to marry either a native or an immigrant, while keeping their own identity. When the cultural gap is not small enough, the equilibrium exists only for $p<\frac{r}{\alpha} \frac{1}{e^{\theta(n-m)^{2}}-1}$. Since $p>0.5$, this means that the population is balanced, in the sense that the gap between the proportions of immigrants and natives in the population is small enough. On the one hand, this creates the incentive for intermarriage, but on the other hand, it doesn't create the incentive to assimilate. In this case we actually see intermarriage between the natives and the immigrants, with both types of individuals holding on to their own culture. We expect that the children 
of the couple, growing up in a household with two cultures, will create a new culture, merging the two different cultures of their parents. In this case, the culture of the natives will not survive over time and we will see new cultures developing. Exogamy without Assimilation is widespread in countries like the US, where the entire population consists of migrants. As a result, we see the development of an "American culture", a culture that builds a bridge between people from different ethnic backgrounds, in spite of the cultural differences between them.

We will now analyze another kind of intermarriage between natives and immigrants, one where one group adopts the behavior of the other group, and where Exogamy with Assimilation exists.

\subsection{Exogamy with Assimilation Equilibrium}

In the scenario discussed in this section, natives stay loyal to their own identity and customs. In addition they are selective and agree to only marry partners with similar behavior. In this scenario, the immigrants neglect their identity and assimilate into the natives' group. This of course means that immigrants are unselective and marry their first date.

\section{Proposition 5:}

When the immigrants are a small enough minority in the singles' population, they will completely integrate into the natives' group by adopting the natives' customs and marrying with them.

Algebraically, the condition for the situation described in Proposition 5 is $p>\frac{(r+\alpha)\left(1-e^{-(n-m)^{2}}\right)}{r+\alpha\left(1-e^{-(n-m)^{2}}\right)}$, which yields us our third corollary:

\section{Corollary 3:}

a. When the cultural difference between the natives and the immigrants is small enough, the Exogamy with Assimilation is always an equilibrium.

b. When the cultural difference between the natives and the immigrants is large enough, the Exogamy with Assimilation is not an equilibrium. 
Our basic assumption, represented by equations (1) and (2), was that individuals prefer to marry someone from their own culture. However, we see that even when this is the situation, the search process may lead to intermarriage. We presented a characterization for two kinds of intermarriage. The combination of corollaries 1-3 tells us that both kinds are exogamy equilibrium when the cultural difference between natives and immigrants is small enough and there is no cost for adopting the second group's norms of behavior or marrying a member of the second group. The corollaries also tell us that when the cultural difference between the natives and the immigrants is large enough, no exogamy exists and the unique equilibrium is the Segregating Equilibrium for any inner division of the singles' market. In this case, the cost of changing one's identity or marrying someone who is different is too high, which causes the other potential patterns of behavior not to be the best response.

The difference between the two kinds of exogamy is related to small but not small enough gaps between natives and immigrants. In this case, the question of assimilation depends on the size of the different groups. In the first type of exogamy without assimilation, immigrants and natives agree to marry each other, but each of the individuals holds on to their own culture and customs, refusing to adopt his spouse's norms of behavior. In proposition 4, we saw that this situation takes place when the population is balanced, meaning that the gap between the proportions of immigrants and natives in the population is small enough. In the second situation without assimilation, one group in the population completely integrates into the other group and therefore when a couple gets married their behavior and customs are identical. From proposition 5 we learn that this situation takes place when there is a large enough gap between the proportion of immigrants and natives in the population, creating the incentives for the minority to assimilate into the majority group.

A significant distinction between the two types of exogamy relates to our expectations regarding the culture which the offspring of the natives and the immigrants will choose to adopt. When talking about Exogamy without Assimilation Equilibrium, we expect that the children of a couple, who grow up with two parents each with a different culture, will create a new culture, a middle ground that represents both cultures. In this case the culture of the natives will not survive over time and we will see new cultures evolving. Alternatively, when the minority group completely integrates into the majority, adopting their customs and marrying partners from the majority group, the children are exposed only to the natives' customs from 
the very first moment of their lives. In this case it is expected that the local culture will survive over time, while the minority culture will disappear.

\section{Assimilation: Discussion and Concluding Remarks}

Looking for a marriage partner is a complicated process that requires decisions regarding the loyalty of the individual to their own identity and regarding the type of spouses that the individual agrees to marry. The economic literature that deals with the search processes in the marriage market focuses on the second decision, the identity of one's spouse, and assumes that individuals cannot change their own identity. This kind of analysis suits situations where the identity of the individuals is exogenous, e.g. when the individuals are recognized by their race, their age, and so on. However, many of the characteristics that distinguish between individuals are endogenous, and people can decide to change them. For example, people can change their religious observance, their political attitudes, or their norms of behavior, if they expect that this will increase their probability of finding a spouse. This kind of decisions is especially relevant in communities that consist of a few cultural groups for example natives and immigrants. When this is the case, both the natives and the immigrants need to decide whether they agree to marry someone who comes from another culture and has different customs and norms of behavior. In addition, under these circumstances, people are required to examine their loyalty to their own culture, and to decide if they are ready to compromise and to adopt their partners' customs.

In this paper, we examined both decisions which singles, both natives and immigrants, are required to make in the process of searching for a spouse: the decision regarding their own identity and the decision regarding the identity of acceptable spouses. In the literature, the considerations which determine the degree to which the natives and the immigrants encourage or discourage the assimilation process include monetary considerations, such as the locals' concerns regarding wages depression and alternatively the immigrants' willingness to improve their wages (see for example Chiswick (1977), Chiswick (1978) and Deutsch, Epstein and Lecker (2006)). However, considerations regarding the culture and identity of both groups are also involved (Lazear (1999), Gang and Zimmerman (2000), Epstein and Gang (2009), Anas (2002)). In regards to this, immigrants that decide to assimilate into the native population suffer from a loss of their identity and culture. Similarly, the native 
population might be concerned about the influence that a foreign culture may have, and therefore may choose to take active steps to discourage the assimilation process. In many countries, the expansion of immigration through the years led to discussions regarding their willingness to expose their culture to potential influences from other cultures. Moreover, governments are required to decide which actions to use in order to try and minimize the influence of the foreign culture. Often, there are concerns that legitimate actions aimed at preserving the local culture, will be interpreted as harassment. Both in Europe and the USA, political parties take either pro- or antiimmigrant stances. Debates regarding immigration policies and assimilation are also very common among the general public (see for example Miller (1999) for the Australian case and Bauer, Lofstrom and Zimmermann (2000) for OECD countries).

Focusing on the marriage market, we illustrate potential equilibria for the assimilation process of immigrants into the native population. These potential equilibria depend on the cultural gaps between the natives and the immigrants and the different distributions of the singles' market among natives and immigrants. We conclude that when the cultural gap between the different groups is very large, each group prefers segregation, keeping its own culture, as well as avoiding marriage to partners from other groups. We referred to this situation as the "Segregating Equilibrium", where, in a way, this equilibrium is quite intuitive because of our basic assumption that people prefer to marry within their own community. As we discussed in the paper, a segregated society can also be a result of the exclusion against the minority by the majority group. These circumstances give rise to a higher degree of social tension in comparison to the mutual segregating equilibrium, since the minority is willing to integrate into the majority group through marriage but the majority resists. We showed that the search process may also yield exogamy equilibria when the cultural gaps between the groups are relatively low. We discussed two different kinds of intermarriage. When the population is balanced and the proportions of natives and immigrants are similar, exogamy without assimilation is common. This means that in a marriage, both partners hold on to their own cultures. In this scenario, it is reasonable to assume that the children of this couple may create a cultural bridge between the cultures of the parents, developing a new culture. In this case the culture of the natives will not survive over time and we will see new cultures evolving. Alternatively, when the proportion of one group in the population is significantly higher than the proportion of the other group, the minority group integrates 
completely into the majority, adopting their customs and marrying partners from the majority group. Over time, this may result in the survival of the local culture and the disappearance of the minority culture. We can see that one distinction, between the different potential equilibria discussed in the paper, relates to the culture which the offspring of natives and immigrants will choose to adopt. In the future we intend to further analyze the phenomena of assimilation through marriage. Specifically, we intend to introduce the evolutionary process that describes the formation of a new culture. 


\section{References}

Anas, A. (2002): "Prejudice, Exclusion and Compensating Transfers: The Economics of Ethnic Segregation". Journal of Urban Economics, 52(3), 409-32.

Bauer, T., M. Lofstrom and K.F. Zimmermann (2000): "Immigration Policy, Assimilation of Immigrants and Natives' Sentiments Towards Immigrants: Evidence from 12 OECD Countries". Swedish Economic Policy Review, 7, 11-53.

Bauer,T, Epstein G.S. and Gang, I.N (2007) "The influence of stocks and flows on migrants' locational choices" Resurrect in Labor Economic 26: 199-229.

Bisin, A. and T. Verdier (2000): "'Beyond the melting pot': cultural transmission, marriage, and the evolution of ethnic and religious traits". Quarterly Journal of Economics, 115(3), 955-988.

Bisin, A., G. Topa and T. Verdier (2004): "Religious Intermarriage and Socialization in the U.S.". Journal of Political Economy, 112, 615-664.

Boeri, T., G. Hanson and B. McCormick (2002): "Immigration Policy and the Welfare System". Oxford University Press.

Borjas, G.J. (2000): "Ethnic Enclaves and Assimilation”. Swedish Economic Policy Review, 7, 89-122.

Burdett, K. and M.G. Coles (1997): "Marriage and Class". Quarterly Journal of Economics, 112(1), 141-168.

Chiswick, B.R. (1977): "Sons of Immigrants: Are They at an Earnings Disadvantage?". American Economic Review, 67, 376-380.

Chiswick, B.R. (1978): "The Effect of Americanization on the Earnings of ForeignBorn Men". Journal of Political Economy, 86(5), 897-922.

Chiswick, C.U. (2009): "The Economic Determinants of Ethnic Assimilation". Journal of Population Economics, 22(4), 859-880.

Cornelius, T.J. (2003): "A Search Model of Marriage and Divorce". Review of Economic Dynamics, 6(1), 135-155.

Deutsch, J., G.S. Epstein and T. Lecker (2006): "Multi-Generation Model of Immigrant Earnings: Theory and Application". Research in Labor Economics, 24, 217-234.

Diamond, P.A. (1982): "Aggregate Demand Management in Search Equilibrium". Journal of Political Economy, 90, 881-894.

Epstein G.S. (2010) "Informational Cascades and the Decision to Migrate" in Gil S. Epstein, and Ira N. Gang, Ed (2010), Frontiers of Economics and Globalization, volume 8, Migration and Culture, Emerald Group Publishing Limited. 
Epstein, G.S. and I.N. Gang (2009): "Ethnicity, Assimilation and Harassment in the Labor Market". Research in Labor Economics, 29, 67-90

Epstein G.S. and Gang I.N. (2010a) "A Political Economy of the Immigrant Assimilation: Internal Dynamics" in Gil S. Epstein, and Ira N. Gang, Ed (2010), Frontiers of Economics and Globalization, volume 8, Migration and Culture, Emerald Group Publishing Limited.

Epstein G.S. and Gang, I.N. (2010b) "Migration and Culture" in Gil S. Epstein, and Ira N. Gang, Ed (2010), Frontiers of Economics and Globalization, volume 8, Migration and Culture, Emerald Group Publishing Limited.

Fraga, L.R. and G.M. Segura (2006): "Culture Clash? Contesting Notions of American Identity and the Effects of Latin American Immigration". Perspective on Politics, 4, 279-287.

Fukuyama, F. (2006): "Identity, Immigration and Liberal Democracy". Journal of Democracy, 17(2), 5-20.

Furtado, D. and N. Theodoropoulos (2009): "I'll Marry You if You Get Me a Job: Marital Assimilation and Immigrant Employment Rates". International Journal of Manpower, 30, 116-126.

Furtado, D. and N. Theodoropoulos (2010): "Why Does Intermarriage Increase Immigrant Employment? The Role of Networks". The B.E. Journal of Economic Analysis and Policy, 10(1), Article 101.

Gang, I.N. and K.F. Zimmermann (2000): "Is Child Like Parent? Educational Attainment and Ethnic Origin". Journal of Human Resources, 35, 550-569.

Huntington, S. P. (2004). "Who Are We? The Challenges to America's National Identity". New York: Simon and Schuster.

Lazear, E.P. (1999): "Culture and Language". Journal of Political Economy, 107, S95-S126.

Meng, X. and R.G. Gregory (2005): "Intermarriage and the Economic Assimilation of Immigrants". Journal of Labor Economics, 23(1), 135-176.

Meng, X. and D. Meurs (2009): "Intermarriage, Language, and Economic Assimilation Process: A Case Study of France". International Journal of Manpower, 30, 127-144.

Miller, P.W. (1999): "Immigration Policy and Immigrant Quality: The Australian Points System". American Economic Review, 89(2), 192-97.

Mortensen, D.T. (1982): "The Matching Process as a Non-Cooperative Bargaining Game". In: J.J. McCall (Ed.) The Economics of Information and Uncertainty, New York: NBER Conference Volume.

Mortensen, D.T. and C.A. Pissarides (1999): "Unemployment Responses to 'SkillBiased' Technology Shocks: The Role of Labour Market Policy". Economic Journal, 109(455): 242-65. 
Pissarides, C.A. (2000): "Equilibrium Unemployment Theory", $2^{\text {nd }}$ edition. Cambridge, MA: MIT Press.

Shimer, R. and L. Smith (2000): “Assortative Matching and Search". Econometrica, 68(2): 343-69.

Venturini, A. (2004): "Post-War Migration in Southern Europe, 1950-2000. An Economic Approach". Cambridge University Press. 


\section{Appendix}

\section{Proof of Proposition 1:}

Let us begin with the natives' preferences. According to equations (1) and (3) the periodic utility of an individual who was born as native (no matter how he behaves in equilibrium), in each possible situation, is:

(i) $r N_{x}^{n}=e^{-(x-n)^{2}}$

(ii) $r N_{x}^{m}=e^{-(x-n)^{2}-\theta(m-n)^{2}}$

(iii) $r N S_{x}=\alpha\left(\lambda\left(N_{x}^{n}-N S_{x}\right)+(1-\lambda) \max \left\{N_{x}^{m}-N S_{x}, 0\right\}\right)$

Suppose that $N S_{x}=N_{x}^{m}$. Then (iii) becomes:

$e^{-(x-n)^{2}-\theta(m-n)^{2}}=\alpha \lambda\left(\frac{e^{-(x-n)^{2}}}{r}-\frac{e^{-(x-n)^{2}-\theta(m-n)^{2}}}{r}\right)$

And after simplifying: $\lambda=\frac{r}{\alpha} \frac{1}{e^{\theta(m-n)^{2}-1}}$. This is the critical value for indifference between remaining single and marrying an immigrant. $\lambda>\frac{r}{\alpha} \frac{1}{e^{\theta(m-n)^{2}-1}}$ yields $N S_{x}>N_{x}^{m}$. In a similar way, one can show that when $1-\lambda>\frac{r}{\alpha} \frac{1}{e^{\theta(m-n)^{2}-1}}$ it yields $M S_{x}>M_{x}^{n}$, meaning that immigrants prefer remaining single over marrying natives. 


\section{Segregating Equilibrium:}

First, we would like to examine the conditions that assure that an individual would not benefit from changing his marriage decision from being selective to being unselective. Given the behavior of all the agents in the Segregating Equilibrium: $\lambda=p$ meaning that the fraction of natives in the population of singles in equilibrium equals exactly their initial fraction. Substituting $\lambda=p$ in the expression appears in Proposition 1 and based on our assumption $p>1-p$ we conclude that the marriage decision in the segregating equilibrium is stable when:

$$
\text { (A-1) } 1-p>\frac{r}{\alpha} \frac{1}{e^{\theta(n-m)^{2}}-1} \text {. }
$$

We now turn to the social belonging decision. We focus on a single individual and would like to find the conditions under which he prefers to keep his original social belonging rather than assimilating into the other group $\left(N S_{n}>N S_{m}\right.$ and $\left.M S_{m}>M S_{n}\right)$. Notice, that changing one's social belonging is costly and can be beneficial only to a single individual because of the potential increase in the probability of getting married. Let's look at an unmarried immigrant. Using $\lambda=p$, we can see that when the immigrant remains loyal to his identity his periodic payment equals:

$$
r M S_{m}=\alpha(1-p)\left(M_{m}^{m}-M S_{m}\right)=\alpha(1-p)\left(\frac{1}{r}-M S_{m}\right)
$$

Notice, that (A-2) is based on the behavior of the agents in the Segregating Equilibrium meaning that an immigrant who keeps his original ethnic behavior can only marry immigrants.

Simplifying (A-2) yields:

$$
M S_{m}=\frac{\alpha(1-p)}{r(r+\alpha(1-p))}
$$

If an immigrant who is single decides to change his social belonging and integrate into the natives' group he has two options: i. to be selective and agree to only marry immigrants. ii. to be unselective and agree to marry his first date. Choosing the first option will leave the agent with no marriage possibilities (the other immigrants will 
reject him because of his native-like social behavior). This means that in this case $M S_{n}=0$ and hence this option cannot be beneficial for the agent. Regarding the second option, becoming unselective will enable the agent to marry natives (and only them), thus:

$$
r M S_{n}=\alpha p\left(M_{n}^{n}-M S_{n}\right)=\alpha p\left(\frac{e^{-(1+\theta)(n-m)^{2}}}{r}-M S_{n}\right)
$$

And after simplifying:

$$
M S_{n}=\frac{\alpha p e^{-(1+\theta)(n-m)^{2}}}{r(r+\alpha p)}
$$

The immigrant prefers to keep his original social belonging when (A-3) is greater than $(\mathrm{A}-5)$ :

$$
\frac{\alpha(1-p)}{r(r+\alpha(1-p))}>\frac{\alpha p e^{-(1+\theta)(n-m)^{2}}}{r(r+\alpha p)}
$$

Similar calculations yield that a native prefers to keep his original social belonging when:

$$
\frac{\alpha p}{r(r+\alpha p)}>\frac{\alpha(1-p) e^{-(1+\theta)(n-m)^{2}}}{r(r+\alpha(1-p))}
$$

However since $\mathrm{p}>0.5$ (A-7) trivially holds.

We conclude that the necessary and sufficient conditions for the Segregating Equilibrium to hold are (A-1) and (A-6). 


\section{Exogamy without Assimilation Equilibrium:}

We begin again with the marriage decision and look for the condition that assures us that no one can benefit from a deviation from being unselective to being selective. Given the behavior of the other agents in the Exogamy without Assimilation Equilibrium: $\lambda=p$. Using proposition 1 we can see that remaining unselective is a stable decision when $p<\frac{r}{\alpha} \frac{1}{e^{\theta(n-m)^{2}}-1}$.

Regarding the social belonging decision, we will now show that for any value of $p$, given the behavior of the other agents in this equilibrium, remaining in one's original ethnic group is a stable decision.

Let us begin with the natives. If the native who is single remains loyal to his own ethnic group:

$$
r N S_{n}=\alpha\left(p\left(\frac{1}{r}-N S_{n}\right)+(1-p)\left(\frac{e^{-\theta(n-m)^{2}}}{r}-N S_{n}\right)\right)
$$

If the single who is native integrates into the immigrants' group, his utility becomes:

$$
r N S_{m}=\alpha\left(p\left(\frac{e^{-(n-m)^{2}}}{r}-N S_{m}\right)+(1-p)\left(\frac{e^{-(1+\theta)(n-m)^{2}}}{r}-N S_{m}\right)\right)
$$

It can be seen, that $N S_{n}>N S_{m}$ for any value of $p$. Similarly, for any value of $p$ we see that $M S_{m}>M S_{n}$. In other words, given that all of the individuals agree to marry both natives and immigrants, no one has an incentive to bear the cost of changing his/her identity. 


\section{Exogamy with Assimilation Equilibrium:}

Given the behavior of the agents in this scenario, the individuals can only marry individuals behaving like natives, and $\lambda=1$. Therefore, it follows that no one can benefit from changing their marriage decision (natives are indifferent between being selective and unselective while immigrants sustain a loss if they deviate and become selective).

We would like to examine whether an individual can benefit from deviating and behaving like an immigrant. An unmarried individual born as a native, has the maximal possible utility (he keeps his identity and has probability 1 to marry his first date). Therefore, he has no incentive to deviate and adopt the immigrants' customs.

Regarding the assimilated immigrant, we would like to examine whether it is beneficial for him to return to his original culture as an immigrant, given that all the other immigrants integrated into the natives group. When the assimilated immigrant stays in the natives group, he can marry $100 \%$ of the singles population and his expected periodic payment from the marriage is $e^{-(1+\theta)(n-m)^{2}}$ (because he pays both the cost of changing his own identity by adopting the native's customs and the cost of marrying a native). His utility is therefore:

$$
r M S_{n}=\alpha\left(\frac{e^{-(1+\theta)(n-m)^{2}}}{r}-M S_{n}\right)
$$

After simplification:

$$
M S_{n}=\frac{\alpha e^{-(1+\theta)(n-m)^{2}}}{r(r+\alpha)}
$$

Returning to his original behavior reduces the fraction of singles who agree to marry this immigrant to $1-p$ (the other assimilated immigrants) but on the other hand increases the expected periodic payment from the marriage to $e^{-\theta(n-m)^{2}}$ because the individual only pays the cost of the marriage with someone who behaves as a native. This gives us:

$$
r M S_{m}=\alpha(1-p)\left(\frac{e^{-\theta(n-m)^{2}}}{r}-M S_{m}\right)
$$


Or:

(A-13)

$$
M S_{m}=\frac{\alpha(1-p) e^{-\theta(n-m)^{2}}}{r(r+\alpha(1-p))}
$$

The identity decision for this assimilated immigrant is the best response when the deviation is not beneficial for him (when (A-11) is greater than (A-13)). This occurs when $p>\frac{(r+\alpha)\left(1-e^{-(n-m)^{2}}\right)}{r+\alpha\left(1-e^{-(n-m)^{2}}\right)}$ 